\title{
Outcomes of vaginal hysterectomy combined with anterior and posterior colporrhaphy for pelvic organ prolapse: a single center retrospective study
}

\author{
Ju Hee Kim, MD*, So Young Lee, MD*, Hee Dong Chae, MD, PhD, Yoon Kyung Shin, MD, Sa Ra Lee, MD, PhD,
} Sung Hoon Kim, MD, PhD

Department of Obstetrics and Gynecology, Asan Medical Center, University of Ulsan College of Medicine, Seoul, Korea

\section{Objective}

To evaluate the efficacy of vaginal hysterectomy combined with anterior and posterior colporrhaphy (VH APR) for the management of pelvic organ prolapse (POP).

\section{Methods}

A total of 610 patients with POP who underwent VH APR from January 2010 to June 2019 at Asan Medical Center were included in this study. We analyzed the patient characteristics and surgical outcomes. In addition, we compared the POP quantification system (POP-Q) pre- and postoperatively at 2 weeks, 3 months, and 1 year, and analyzed the risk factors for recurrence.

\section{Results}

The mean age of the patients was $65.5 \pm 7.6$ years. The most common preoperative POP-Q stage was stage $2(60.8 \%)$, followed by stage $3(35.9 \%)$. Complications were identified during surgery in $1.6 \%$ of the patients. The most common postoperative complication (6.4\%) was voiding difficulty. All POP-Q scores significantly decreased at 1 year after surgery $(P<0.0001)$. The recurrence rate was $9.6 \%$, and most recurrences $(77.5 \%)$ occurred in the anterior compartment. An advanced stage of preoperative POP was a risk factor for recurrence (stage 3 or 4 vs. stage 1 or 2; odds ratio $[\mathrm{OR}], 5.337,95 \%$ confidence interval $[\mathrm{Cl}], 2.58-11.036, P<0.0001)$. Only two patients underwent surgical correction for POP recurrence, and most of the remaining patients did not undergo further treatment for prolapse.

\section{Conclusion}

VH APR is a safe and effective surgical procedure for POP, with a low recurrence rate. In addition, advanced preoperative stage was the only risk factor for recurrent POP.

Keywords: Vaginal hysterectomy; Pelvic organ prolapse; Anterior colporrhaphy; Posterior colporrhaphy

\section{Introduction}

Pelvic organ prolapse (POP) is defined as the downward descent of pelvic organs that results in the protrusion of the vagina, uterus, or both from the vaginal introitus [1]. The prevalence of POP has ranged from $3 \%$ to $41 \%$ in previous studies, because the definition for POP varies from study to study [2-7]. Pelvic organ support deteriorates with age, and hence, a majority of women over 50 years of age experience POP. The prevalence of POP continues to rise owing to an increase in the elderly population [8]. In Korea, the prevalence of POP was much lower than that in previous studies
Received: 2021.07.15. Revised: 2021.09.08. Accepted: 2021.10.13. Correspondence author: Hee Dong Chae, MD, PhD

Department of Obstetrics and Gynecology, Asan Medical Center, University of Ulsan College of Medicine, 88 Olympic-ro 43-gil, Songpa-gu, Seoul 05505, Korea

E-mail: hdchae@amc.seoul.kr https://orcid.org/0000-0003-0129-9422

${ }^{\star}$ These authors contributed equally to this work.

Articles published in Obstet Gynecol Sci are open-access, distributed under the terms of the Creative Commons Attribution Non-Commercial License (http://creativecommons. org/licenses/by-nc/3.0/) which permits unrestricted non-commercial use, distribution, and reproduction in any medium, provided the original work is properly cited.

Copyright $\odot 2022$ Korean Society of Obstetrics and Gynecology 


\section{Obstetrics \& Gynecology Science}

Ju Hee Kim, et al. Efficacy of vaginal hysterectomy

(180 per 100,000 population for women over 50 years), as the definition of POP excluded subjective symptoms and included only POP diagnosed by doctors. In addition, the rate of POP surgery peaked among those aged approximately 70 years [7].

Patients with symptomatic POP who decline or show no improvement with nonsurgical treatment are candidates for surgical treatment. The route of repair (abdominal or vaginal approach) depends on a multitude of patient factors (age, presence of uterus, site of prolapse, comorbidities) and the surgeon's preference. Previous studies have shown that the vaginal approach has a shorter operation time (OT) and hospital stay, and a lower complication rate than the abdominal approach [9-11]. Therefore, surgery via the vaginal approach may be preferred for elderly or medically compromised patients, as it is associated with low morbidity.

There are various surgical methods for the vaginal approach, including reconstructive procedures, obliterative procedures, and procedures that preserve the uterus with a synthetic mesh [12]. To date, hysterectomy is the recommended procedure for the treatment of POP; however, clinical data on its effectiveness compared to uterine preservation are limited. A recent cohort study of 100,000 women demonstrated that hysterectomy for POP is associated with a decreased risk of POP recurrence at any site: anterior, apical, and posterior [13]. There are limited studies on the efficacy of vaginal hysterectomy combined with anterior and posterior colporrhaphy (VH APR), and only a few studies have compared colporrhaphy with other POP surgical methods. Anterior colporrhaphy has a high surgical success rate of $70-89 \%$, although the results of surgical success in comparison to those with mesh surgery are controversial according to the definition of anatomic success [14-16]. In contrast, posterior colporrhaphy has proven to be effective in correcting the posterior vaginal compartment compared to other surgical methods $[16,17]$. In addition, one study revealed that VH APR is effective in treating uterine prolapse at stage $>2$ [18]. However, data on the efficacy of APR are unclear, and further clinical studies must be undertaken.

Limited data are available on VH APR and its outcomes in POP treatment in the Korean population. This study aimed to report the surgical outcomes of VH APR over the past 10 years, evaluate the complications of surgery, and calculate the recurrence rate to identify the safety and efficacy of $\mathrm{VH}$ APR.

\section{Materials and methods}

\section{Study design and patients}

The medical records of all patients who underwent VH APR for POP at Asan Medical Center from January 2010 to June 2019 were reviewed retrospectively. The exclusion criteria were as follows: patients who underwent APR using a mesh, and whose $\mathrm{VH}$ was performed by surgeons who performed less than one $\mathrm{VH}$ a month in their clinical practice. In total, 610 women were included in the analysis.

The following variables were included for patient characteristics: age, body mass index (BMI), number of vaginal deliveries, menopause status, previous pelvic surgery, and associated medical history. All patients underwent preoperative ultrasonography and Pap smear to determine whether they had a risk of malignancy. In addition, all patients underwent a preoperative POP-quantification (POP-Q) examination, performed by a single physician, for the evaluation of stage and the six points ( $A a, B a$ for anterior vaginal wall; C, D for upper vagina; $A p, B p$ for posterior vaginal wall), as well as the total vaginal length (TVL) of the POP-Q system [19]. The following variables were included in the surgery-related data: concomitant surgery, OT (incision to close), estimated blood loss (EBL), pre- and postoperative hemoglobin levels $(\mathrm{Hb})$, transfusion rate, complications during and after surgery, length of hospital stay, and duration of Foley catheterization.

To evaluate the postoperative recurrence rate, the POPQ system was evaluated at 2 weeks, 3 months, and 1 year after surgery. The same physician performed the tests before and after the surgery to eliminate bias due to inter-surgeon variation. At any point during the follow-up, we defined recurrence of POP as mentioned in a previous study [20], when the $\mathrm{Aa}, \mathrm{Ba}, \mathrm{C}, \mathrm{Ap}$, and $\mathrm{Bp}$ scores for objective recurrence were higher than $-1 \mathrm{~cm}$ (over stage 2 ) or if the patient had subjective recurrence symptoms (vaginal bulging or pressure) without objective recurrence.

This study was approved by the Asan Medical Center Institutional Review Board (approval No. 2019-1137).

\section{Surgical procedures}

All patients were placed in the dorsal lithotomy position under general anesthesia, and a Foley catheter was inserted into the bladder before the first incision was made. A circular incision on the cervix and a triangle-shaped incision on the anterior vaginal wall were made. The anterior vaginal 


\section{Obstetrics \& Gynecology Science}

Vol. 65 , No. 1, 2022

Table 1. Patient baseline and preoperative characteristics

\begin{tabular}{|c|c|}
\hline Characteristic & Value \\
\hline Age (yr) & $65.5 \pm 7.6(39,87)$ \\
\hline BMI $\left(k g / m^{2}\right)$ & $24.97 \pm 2.7$ \\
\hline Vaginal parity & $3(0,8)$ \\
\hline \multicolumn{2}{|l|}{ Menopausal status } \\
\hline Premenopausal & $20(3.3)$ \\
\hline Postmenopausal & $590(96.7)$ \\
\hline Previous surgery & $71(11.6)$ \\
\hline Cesarean section & $18(2.95)$ \\
\hline SUI & $34(5.6)$ \\
\hline PR & $10(1.6)$ \\
\hline Prolapse & $9(1.5)$ \\
\hline \multicolumn{2}{|l|}{ Comorbidity } \\
\hline DM & $97(15.9)$ \\
\hline HTN & $282(46.2)$ \\
\hline Pulmonary & $34(5.6)$ \\
\hline Urology & $36(5.9)$ \\
\hline \multicolumn{2}{|l|}{ Initial POP-Q } \\
\hline $\mathrm{Aa}(\mathrm{cm})$ & $1.00(-3,3)$ \\
\hline $\mathrm{Ba}(\mathrm{cm})$ & $1.00(-3,6)$ \\
\hline$C(\mathrm{~cm})$ & $0(-5,6)$ \\
\hline $\mathrm{Ap}(\mathrm{cm})$ & $-2(-3,3)$ \\
\hline $\mathrm{Bp}(\mathrm{cm})$ & $-2(-3,5)$ \\
\hline TVL $(\mathrm{cm})$ & $7(6,10)$ \\
\hline \multicolumn{2}{|l|}{ Initial stage } \\
\hline 1 & $3(0.5)$ \\
\hline 2 & $371(60.8)$ \\
\hline 3 & $219(35.9)$ \\
\hline 4 & $17(2.8)$ \\
\hline Preoperative Hb (g/dL) & $12.85 \pm 1.08$ \\
\hline
\end{tabular}

Values are presented as mean \pm standard deviation (range), median (range), or number (\%).

BMI, body mass index; SUI, stress urinary incontinence; PR, posterior colporrhaphy (repair); DM, diabetes mellitus; HTN, hypertension; POP-Q, pelvic organ prolapse quantification; TVL, total vaginal length; $\mathrm{Hb}$, hemoglobin.

wall and bladder were then dissected. The peritoneum was opened, a retractor was inserted, and the bladder was lifted. The peritoneum was opened through the posterior cul de sac. The uterosacral ligament, paracervical tissue, and uterine artery pedicle were clamped, sutured, and cut. After the uterus was rotated, both the round ligaments and the tubo-
Table 2. Intra-and peri-operative surgery-related outcomes

\begin{tabular}{|c|c|}
\hline Characteristic & Value \\
\hline Combined operation & $33(5.4)$ \\
\hline TOT & $11(1.8)$ \\
\hline Adnexa & $18(2.95)$ \\
\hline Other & $4(0.66)$ \\
\hline Operation time (min) & $86.5 \pm 20.96$ \\
\hline $\mathrm{EBL}(\mathrm{mL})$ & $72.7 \pm 65.8$ \\
\hline Postoperative Hb (g/dL) & $11.1 \pm 1.2$ \\
\hline Difference in $\mathrm{Hb}(\mathrm{g} / \mathrm{dL})$ & $1.7 \pm 1.0$ \\
\hline Transfusion & $6(0.98)$ \\
\hline Hospital stays (days) & $3(3-9)$ \\
\hline Duration of the Foley catheterization (days) & $2(2-90)$ \\
\hline Intraoperative complications & $10(1.6)$ \\
\hline Bladder injury & $4(0.7)$ \\
\hline Hematuria & $5(0.8)$ \\
\hline Rectal injury & $1(0.2)$ \\
\hline Postoperative complications & $69(11.3)$ \\
\hline Voiding difficulty & $39(6.4)$ \\
\hline Fever & $14(2.3)$ \\
\hline Vaginal bleeding & $2(0.3)$ \\
\hline Hematoma & $2(0.3)$ \\
\hline Stump dehiscence & $1(0.2)$ \\
\hline Abscess & $1(0.2)$ \\
\hline Peritonitis & $1(0.2)$ \\
\hline WF & $1(0.2)$ \\
\hline Ureteral obstruction & $1(0.2)$ \\
\hline Other (arrhythmia, elevated liver enzymes) & $7(1.2)$ \\
\hline
\end{tabular}

Values are presented as mean \pm standard deviation (range), median (range), or number (\%).

TOT, transobturator vaginal tape; EBL, estimated blood loss; $\mathrm{Hb}$, hemoglobin; VVF, vesicovaginal fistula.

ovarian ligaments were clamped, sutured, and cut. In case of an adnexal mass, salpingo-oophorectomy or simple cystectomy was performed. The uterus was then removed. After reperitonization, a lower uterosacral ligament suspension (USLS) for vault support and APR was performed.

All patients received the following standard postoperative care: the Foley catheter was retained until postoperative day 2; after removing the Foley catheter, the voiding pattern was examined for 1 day. The patients were discharged if the selfvoiding volume was $>200 \mathrm{~mL}$, and the residual urine volume was $\leq 100 \mathrm{~mL}$ in the bladder scan. If voiding was difficult 


\section{Obstetrics \& Gynecology Science}

Ju Hee Kim, et al. Efficacy of vaginal hysterectomy

after removing the catheter, the catheter was re-inserted and maintained for another day or two. If the patient suffered bladder injury during the surgery, the catheter was maintained for a few more days in accordance with the consulting urologist's opinion.

\section{Statistical analysis}

Categorical variables are presented as numbers with percentages. Continuous variables are presented as mean \pm standard deviation (SD) or median with range. The differences over time (at baseline, 2 weeks, 3 months, and 1 year) were analyzed using the Friedman test or Wilcoxon signed-rank test for non-normally distributed variables. Significance levels of the post-hoc test were determined by Bonferroni correction for pairwise comparisons of sequences to avoid false-positive results. Since there were six variables $(A a, B a, C, A p, B p$, and TVL), the cut-off $P$-value for significance was $0.05 / 6=0.008$. Logistic regression analyses were performed to identify the independent factors associated with POP recurrence. Statistical analysis was conducted using SAS version 9.4 (SAS Institute, Cary, NC, USA).

\section{Results}

\section{Patient baseline and preoperative characteristics}

A total of 610 patients diagnosed with POP who underwent VH APR were included in this study. The average patient age

Table 3. Comparison of the pre- and postoperative POP-Q system

\begin{tabular}{lccccc}
\hline POP-Q point & Initial $(\mathbf{n}=\mathbf{6 1 0})$ & $\mathbf{2}$ weeks $(\mathbf{n = 6 1 0})$ & $\mathbf{3}$ months $(\mathbf{n}=6 \mathbf{6 7})$ & $\mathbf{1}$ year $(\mathbf{n}=\mathbf{4 1 5})$ & $\boldsymbol{P}$-value \\
\hline $\mathrm{Aa}(\mathrm{cm})$ & $0.598 \pm 1.55$ & $-2.933 \pm 0.30$ & $-2.843 \pm 0.45$ & $-2.704 \pm 0.70$ & $<0.0001$ \\
$\mathrm{Ba}(\mathrm{cm})$ & $0.708 \pm 1.69$ & $-2.948 \pm 0.27$ & $-2.850 \pm 0.43$ & $-2.713 \pm 0.68$ & $<0.0001$ \\
C (cm) & $0.639 \pm 1.48$ & $-6.350 \pm 0.79$ & $-6.328 \pm 0.79$ & $-6.347 \pm 0.84$ & $<0.0001$ \\
Ap (cm) & $-1.618 \pm 1.19$ & $-2.987 \pm 0.11$ & $-2.965 \pm 0.23$ & $-2.971 \pm 0.22$ & $<0.0001$ \\
Bp (cm) & $-1.503 \pm 1.47$ & $-2.990 \pm 0.10$ & $-2.965 \pm 0.23$ & $-2.971 \pm 0.22$ & $<0.0001$ \\
TVL (cm) & $7.303 \pm 0.80$ & $6.402 \pm 0.83$ & $6.387 \pm 0.83$ & $6.424 \pm 0.85$ & $<0.0001$ \\
\hline
\end{tabular}

Values are presented as mean \pm standard deviation.

POP-Q, pelvic organ prolapse quantification; TVL, total vaginal length.

$\mathrm{Aa}$

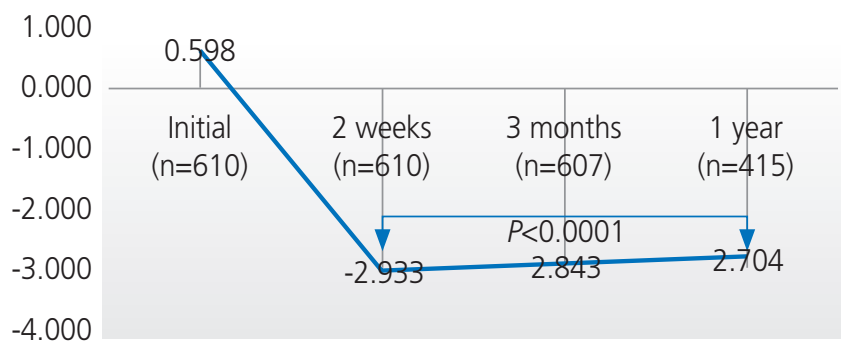

Ap

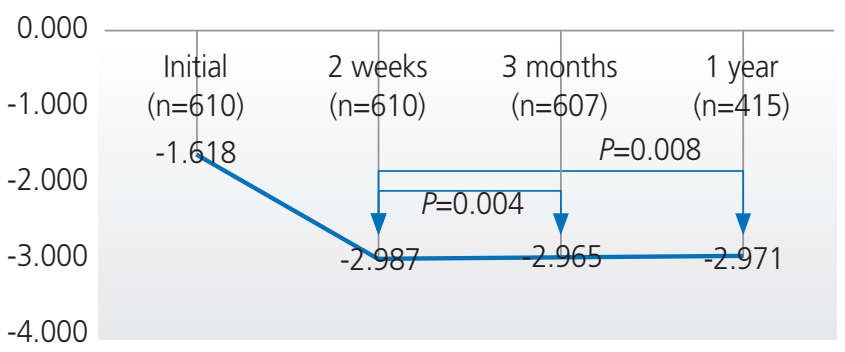

$\mathrm{Ba}$

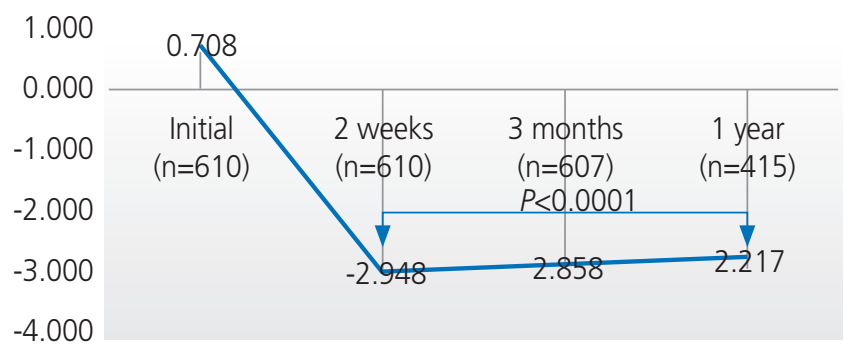

$\mathrm{Bp}$

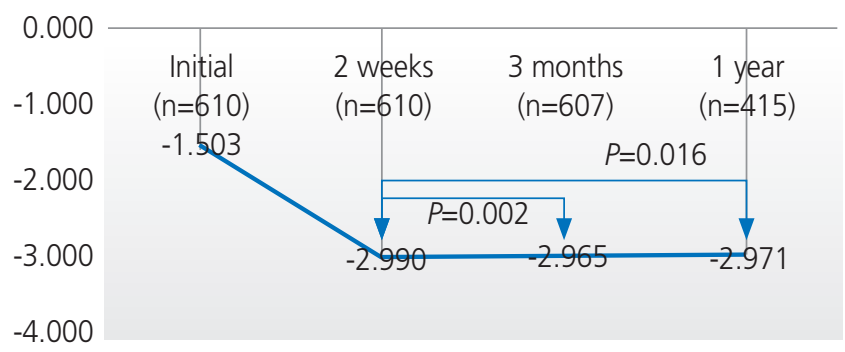

Fig. 1. Comparison of the postperative POP-Q system at 2 weeks, 3 months, and 1 year after surgery. POP-Q, pelvic organ prolapse quantification. 


\title{
Obstetrics \& Gynecology Science
}

\author{
Vol. 65, No. 1, 2022
}

was $65.5 \pm 7.6$ years with a median number of three vaginal deliveries. Most patients (96.7\%) had a menopausal status. Diabetes mellitus (15.9\%) and hypertension (46.2\%) were the most common comorbidities. The most common previous POP-Q stage was stage 2 (60.8\%), followed by POP-Q stage $3(35.9 \%)$; the most severe grade of prolapse was in the anterior compartment ( $\mathrm{Aa}, \mathrm{Ba}$; median $1 \mathrm{~cm})$, followed by the apical compartment ( $C$; median $0 \mathrm{~cm}$ ) (Table 1).

\section{Surgery related outcomes}

Approximately $5 \%$ of the patients underwent a combined operation including transobturator vaginal tape (TOT), adnexal surgery, and other operations, such as labiaplasty, intraligamentary myomectomy, and urethral caruncle excision. The total OT was $86.5 \pm 20.96$ minutes. The mean EBL was less than $100 \mathrm{~mL}(72.7 \pm 65.8 \mathrm{~mL})$, with minimal differences in the pre-and postoperative Hb levels $(1.7 \pm 1.0 \mathrm{~g} / \mathrm{dL})$. Only six patients underwent blood transfusions after surgery. The median length of hospital stay was 3 days, and the median duration of retention of the Foley catheter was 2 days (Table 2).

There were 10 cases $(1.6 \%)$ of intraoperative complications. Of these, four underwent bladder repair for bladder injury. Five patients experienced hematuria during surgery; thus, cystoscopy was performed. Three patients had no specific findings, while two had bladder contusions. The hematuria of five patients showed improvement, and they were discharged without any specific symptoms. One patient had a minor rectal injury during surgery; the colorectal surgeon sutured the injury, and the patient was discharged after routine postoperative care without any specific symptoms. There were 69 cases $(11.3 \%)$ of postoperative complications. The most common complication (6.4\%) was voiding difficulty after Foley catheter removal; however, all patients improved after several days of maintenance on the Foley catheter. There were two cases of severe postoperative complications: one with a left ureteral obstruction and the other with a vesicovaginal fistula (VVF) (Table 2).

\section{Comparison of the pre- and postoperative POP-Q system}

Among the 610 patients, 607 patients (99.5\%) visited the hospital at 3 months, and only 415 patients (68\%) completed the 1-year follow-up. There were statistically significant improvements between the preoperative and postoperative POP-Q scores after 2 weeks, 3 months, and 1 year $(P<0.0001)$
(Table 3). The anterior compartment $(\mathrm{Aa}, \mathrm{Ba})$ gradually prolapsed over 1 year after surgery $(P<0.0001)$, but the change was small at $0.2 \mathrm{~cm}(-2.9 \mathrm{~cm}$ vs. $-2.7 \mathrm{~cm})$ (Fig. 1). The posterior compartment (Ap, Bp) also prolapsed when compared at 2 weeks and 3 months after surgery $(P<0.008)$, but the change was within $0.03 \mathrm{~cm}$. Although the posterior compartment (Ap, Bp) prolapsed when compared postoperatively at 2 weeks and 1 year $(P<0.05)$, the $P$-value was higher than the adjusted $P$-value (0.008); thus, the results were not significant. The apical compartment (C) and TVL did not significantly change within 1 year after surgery (P>0.008) (Fig. 1).

\section{Analysis of POP recurrence}

The symptoms and surgical outcomes at 3 months $(n=607)$ and 1 year $(n=415)$ after surgery were evaluated (Table 4). Vaginal discharge was the most uncomfortable symptom at 3 months after surgery (17.6\%), but it had almost disappeared

Table 4. Symptoms and surgical outcomes at 3 months and 1 year after surgery

\begin{tabular}{|c|c|c|}
\hline Characteristic & $\begin{array}{c}3 \text { months } \\
(n=607)\end{array}$ & $\begin{array}{c}1 \text { year } \\
(n=415)\end{array}$ \\
\hline Symptoms & $285(46.95)$ & $118(28.4)$ \\
\hline Vaginal spotting & $42(6.9)$ & $6(1.5)$ \\
\hline Vaginal discharge & $107(17.6)$ & $8(1.9)$ \\
\hline Leakage sensation & $4(0.7)$ & $2(0.5)$ \\
\hline Urinary frequency & $45(7.4)$ & $30(7.2)$ \\
\hline Urinary urgency & $14(2.3)$ & $5(1.2)$ \\
\hline SUI & $73(12.0)$ & $44(10.6)$ \\
\hline Pelvic pain & $58(9.6)$ & $26(6.3)$ \\
\hline Constipation & $25(4.1)$ & $2(0.5)$ \\
\hline Recurrence & $29(4.8)$ & $40(9.6)$ \\
\hline Anterior compartment & $17 / 29(58.6)$ & $31 / 40(77.5)$ \\
\hline Apical compartment & 0 & 0 \\
\hline Posterior compartment & $6 / 29(20.7)$ & $4 / 40(10)$ \\
\hline Subjective recurrence & $6 / 29(20.7)$ & $5 / 40(12.5)$ \\
\hline \multicolumn{3}{|l|}{ Stage } \\
\hline 0 & $519(85.5)$ & $330(79.5)$ \\
\hline 1 & $65(10.7)$ & $50(12.1)$ \\
\hline 2 & $23(3.8)$ & $34(8.2)$ \\
\hline 3 & 0 & $1(0.2)$ \\
\hline 4 & 0 & 0 \\
\hline
\end{tabular}

Values are presented as percents.

SUI, stress urinary incontinence. 


\section{Obstetrics \& Gynecology Science}

Ju Hee Kim, et al. Efficacy of vaginal hysterectomy

at 1 year after surgery (1.9\%). Urinary frequency $(7.2 \%)$ and stress urinary incontinence $(10.6 \%)$ were the most common symptoms at 1 year after surgery.

The recurrence rate gradually increased from 4.8\% (29/607) at 3 months to $9.6 \%(40 / 415)$ at 1 year after surgery. The site with the most recurrence was the anterior compartment (58.6\% and $77.5 \%$ at 3 months and 1 year, respectively). Subjective recurrence symptoms without objective recurrence occurred in $20.7 \%$ and $12.5 \%$ of the patients at 3 months and 1 year after surgery, respectively. Most patients remained at stages 0 and 1 after 1 year of surgery (91.6\%). Most of the patients with recurrence were in stage $2(8.2 \%)$, one was in stage 3 , and none were in stage 4 (Table 4).

Logistic regression analysis was used to assess the risk factors for POP recurrence (Table 5). The patients' BMI, age, menopausal status, vaginal parity, and previous pelvic surgery were not associated with POP recurrence. However, the odds ratio (OR) for advanced stage of POP (stage 3 or 4 ) at the initial presentation was 4.5 times higher at 3 months after surgery (OR, 4.498; 95\% confidence interval [CI], 1.958-10.333; $P=0.0004)$, and 5.3 times higher at 1 year after surgery $(O R$, $5.337 ; 95 \% \mathrm{Cl}, 2.58-11.036 ; P<0.0001)$ than that of stage 1 and 2 at the initial presentation.

\section{Discussion}

Our study found that VH APR showed significant improvement in the clinical stage of POP patients, which was well maintained up to 1 year after surgery. In addition, VH APR proved to be a safe surgical procedure for elderly patients because it resulted in less EBL and fewer surgical complications.

With advancements in the field of surgery, many surgical methods have emerged as alternatives to traditional $\mathrm{VH}$ for POP patients. Many studies have been conducted on the merits and demerits of uterus preservation surgeries, as well as the efficacy of a mesh in preserving the uterus $[17,21,22]$. A recent randomized controlled trial (RCT) demonstrated that vaginal repair with a mesh or graft was not superior to native tissue repair in terms of improvement of prolapse symptoms, quality of life, and objective failure within 2 years after surgery [14]. In addition, mesh exposure occurred in $12 \%$ of patients. Another RCT comparing vaginal mesh hysteropexy with VH USLS found that there was no difference between the two procedures in terms of re-treatment and recurrence of POP [23]. In addition, VH APR was found to be better than abdominal sacrocolpopexy with preservation of the uterus

Table 5. Logistic regression analyses of POP recurrence

\begin{tabular}{|c|c|c|c|c|}
\hline \multirow{2}{*}{ Characteristic } & \multicolumn{2}{|c|}{3 months (29/607) } & \multicolumn{2}{|c|}{1 year $(40 / 415)$} \\
\hline & OR $(95 \% \mathrm{Cl})$ & $P$-value & OR $(95 \% \mathrm{Cl})$ & $P$-value \\
\hline \multicolumn{5}{|l|}{ BMI $\left(\mathrm{kg} / \mathrm{m}^{2}\right)$} \\
\hline$<25$ & 1 & 0.3559 & 1 & 0.5241 \\
\hline$\geq 25$ & $1.424(0.673,3.013)$ & & $1.236(0.644,2.375)$ & \\
\hline \multicolumn{5}{|l|}{ Age (yr) } \\
\hline$<60$ & 1 & 0.0633 & 1 & 0.2502 \\
\hline$\geq 60$ & $0.472(0.214,1.042)$ & & $0.648(0.309,1.357)$ & \\
\hline \multicolumn{5}{|l|}{ Menopause } \\
\hline No & 1 & 0.2783 & 1 & 0.481 \\
\hline Yes & $0.434(0.096,1.964)$ & & $0.574(0.123,2.687)$ & \\
\hline No. of vagina parity & $1.065(0.787,1.441)$ & 0.6853 & $1.146(0.891,1.473)$ & 0.2887 \\
\hline \multicolumn{5}{|c|}{ Previous pelvic surgery } \\
\hline No & 1 & 0.7679 & 1 & 0.9036 \\
\hline Yes & $0.889(0.406,1.946)$ & & $1.043(0.532,2.045)$ & \\
\hline \multicolumn{5}{|l|}{ Initial stage } \\
\hline 1,2 & 1 & 0.0004 & 1 & $<0.0001$ \\
\hline 3,4 & $4.498(1.958,10.333)$ & & $5.337(2.58,11.036)$ & \\
\hline
\end{tabular}

POP, pelvic organ prolapse; OR, odds ratio; $\mathrm{Cl}$, confidence index; $\mathrm{BMI}$, body mass index. 


\section{Obstetrics \& Gynecology Science}

Vol. 65, No. 1, 2022

in terms of maintaining urogenital function and preventing an overactive bladder [18]. In conclusion, a Cochrane review stated that there was insufficient evidence to use a mesh as a first-line treatment in apical or posterior prolapse as well as prolapse in the anterior compartment (the site most affected by POP) $[17,21,22]$. In this study population, most patients had POP-Q stage 2 or $3(96.7 \%)$, and the anterior compartment was the most affected site $(\mathrm{Aa}$, Ba; median $1 \mathrm{~cm})$; thus, we deemed VH APR without mesh as an appropriate treatment.

We demonstrated that VH APR is a safe operation because it has a short OT, low EBL, and few complications. The OT in our study was the shortest compared to that of previous studies $(86.5 \pm 20.96$ minutes $[n=610]$ vs. $110.7 \pm 42.8$ [ $n=81]$ vs. $156.7 \pm 43.9$ minutes $[n=87])[15,23]$. The blood transfusion rate and the difference in $\mathrm{Hb}$ levels in our study were comparable with those in a previous study (transfusion, $0.98 \%$ [6/610]; difference in $\mathrm{Hb}, 1.7 \pm 1.0 \mathrm{~g} / \mathrm{dL}$ vs. transfusion, $1.9 \%$ [2/108]; difference in $\mathrm{Hb}, 2.0 \mathrm{~g} / \mathrm{dL}$ ) [24]. Abdominal hysterectomy has a blood transfusion rate of $2.18 \%$ $[25,26]$, while $\mathrm{VH}$ has a very low EBL and blood transfusion rate; this demonstrates its safety in the surgical treatment of POP. The intra- and postoperative complications of bladder or ureteral injury were both less than $1 \%$, which is similar to the results of previous studies $[13,18]$. In addition, infectious complications after $\mathrm{VH}$ have been reported to vary from $1 \%$ to $13 \%[13,27]$, but they were found to be less than $1 \%$ in our study. Difficulty in voiding with bladder retention after removal of the urinary catheter was the most common complication (6.4\%). A previous study demonstrated that the urinary retention rate was low on postoperative day 2 (12\%) compared to that on day 1 (35.2\%) or day 3 (21.3\%) [28]. The cause of difficulty in voiding after Foley catheter removal has not been fully identified, and there are no guidelines on the timing of Foley catheter removal after $\mathrm{VH}$. In our study, Foley catheter removal on postoperative day 2 was found to be associated with a low incidence of difficulty in voiding, and all patients showed improvement after several days of maintenance on the Foley catheter.

There were two cases of severe postoperative complications, one with left ureteral obstruction and the other with VVF. One patient was diagnosed with left ureteral obstruction at 7 days post-surgery, and she also showed decreased renal function and left hydronephrosis. Left percutaneous nephrostomy (PCN) was performed, and a double J (DJ) stent was inserted into the ureter. After 8 months of maintenance of the PCN and DJ stents, the patient's kidney function normalized. Another patient underwent bladder repair for bladder injury during surgery, after which a Foley catheter was placed; after 2 weeks, cystoscopy and CT were performed for symptoms of persistent leakage of urine despite maintaining a Foley catheter, and a fistula between the vagina and the bladder, a VVF, was diagnosed. After 3 months of maintenance on the Foley catheter, there was no leakage on cystoscopy, and the Foley catheter was removed. No abnormal findings were found during outpatient observation for the following 3 years. Bladder injury, which is more frequent than ureteral injury, occurs when the prevesical space is dissected. An analysis of 3,076 patients who underwent VH showed one ureteral injury and four VVFs [29]. All VVFs occurred because of bladder laceration during the procedure, with an incidence of $0.13 \%$ in the overall population. Thus, it should be noted that subsequent VVFs can occur if bladder injury occurs during surgery.

Our study found that VH APR showed a significant reduction in POP and a low recurrence rate. However, only $68 \%$ of patients returned at the 1-year follow-up; this may have caused an overestimation of the recurrence rate $(9.6 \%)$. If all patients who did not visit the hospital 1 year after the surgery were assumed to have had no symptoms of recurrence, the recurrence rate would have been $6.6 \%$ to $9.6 \%$. The recurrence rate in this study was much lower than that reported in previous studies $[14,15,23$ ]. Nager et al. [23] evaluated the outcomes of VH with USLS for 3 years, and the cumulative recurrence rates gradually increased from $25 \%$ ( 1 year, $n=21$ ) to $41 \%$ (3 years, $n=28$ ). However, among the cases of recurrence, there was only one case wherein retreatment was required. Similarly, another study showed that the anterior compartment $(\mathrm{Ba} \leq 0)$ was the most common site for recurrence, with a recurrence rate of $29.6 \%(n=24)$, and three patients underwent reoperation within 1 year [15]. Our study also found that the anterior compartment was the most common site of recurrence. Glazener et al. [14] conducted a study on VH APR with native tissue repair versus mesh or graft repair. The study showed that the native repair group showed recurrence of stage $2(45 \%)$, followed by stage $1(32 \%)$ POP at 1 year after surgery, and $6 \%$ of the patients underwent reoperation within 2 years. Three patients required re-treatment for POP recurrence in our study; most of the remaining patients did not require further treatment 


\section{Obstetrics \& Gynecology Science}

Ju Hee Kim, et al. Efficacy of vaginal hysterectomy

for prolapse because the symptoms were not severe. Two patients underwent colpocleisis with posterior colporrhaphy (at 18 months) and APR (at 6 years), both with an initial POP stage of 3 . In the other patient, a pessary was used for 7 years after surgery, as her initial POP stage was 2 . The reason for the low recurrence rate in our study compared to that in previous studies may be attributed to the fact that less than half of the patients (38.7\%) in our study had preoperative advanced POP (stages 3 and 4). However, the comparison with our study is limited because each study had different descriptions of preoperative POP stages and patient characteristics.

Possible reasons for recurrent POP are patient factors, such as age, BMI, and underlying diseases or procedural factors [20]. A systematic review by Vergeldt et al. evaluated 30 risk factors for recurrent POP after native tissue repair and concluded that advanced preoperative stage was the only risk factor (stage 3 or 4 vs. stage 1 or 2, OR, 2.0-3.9, 95\% Cl, 1.0-13.0, $P<0.05)$ for recurrence, and other factors (parity, vaginal delivery, age, and $\mathrm{BMI}$ ) were associated with primary POP [30]. Our study corroborates these findings. In conclusion, the anterior compartment was the most common recurrence site, and the risk factor for recurrence was an advanced stage of POP at the initial presentation. Additional evidence is required to improve preventive strategies and to determine effective surgical or conservative management options.

The strength of this study is that it was a relatively largescale study, as we analyzed 610 patients. Moreover, we excluded surgeries performed by surgeons with less experience in performing $\mathrm{VH}$. Consequently, we analyzed only the results of surgeries performed by a single surgeon. Since one surgeon performed all the operations of VH APR with USLS and POP-Q tests, inter-surgeon bias was eliminated. However, since this was a retrospective study, there may have been selection bias because not all patients visited the outpatient clinic for a year. Further studies are necessary to confirm the long-term outcomes of VH APR.

In conclusion, VH APR demonstrated good surgical outcomes in POP patients, as it was associated with low morbidity and a low recurrence rate. In addition, advanced preoperative stage was the only risk factor for recurrent POP. Many surgeons still prefer VH in POP patients; however, in recent years, there has been an increase in the number of specialized surgeries being performed, such as hysteropexy and sacrocolpopexy. The number of patients with POP is increasing, and various surgical methods are being developed. An appropriate surgical method should be chosen for POP patients after considering patient factors and the operating surgeon's experience and preference.

\section{Conflict of interest}

No potential conflict of interest relevant to this article was reported.

\section{Ethical approval}

This study was approved by the Asan Medical Center Institutional Review Board (approval No. 2019-1137).

\section{Patient consent}

Informed consent was waived due to the retrospective and anonymous nature of the study and participants.

\section{Funding information}

None.

\section{References}

1. Jelovsek JE, Maher C, Barber MD. Pelvic organ prolapse. Lancet 2007;369:1027-38.

2. Hendrix SL, Clark A, Nygaard I, Aragaki A, Barnabei $V$, McTiernan A. Pelvic organ prolapse in the women's health initiative: gravity and gravidity. Am J Obstet Gynecol 2002;186:1160-6.

3. Nygaard I, Barber MD, Burgio KL, Kenton K, Meikle S, Schaffer J, et al. Prevalence of symptomatic pelvic floor disorders in US women. JAMA 2008;300:1311-6.

4. Rortveit G, Brown JS, Thom DH, Van Den Eeden SK, Creasman JM, Subak LL. Symptomatic pelvic organ prolapse: prevalence and risk factors in a population-based, racially diverse cohort. Obstet Gyneco 2007;109:1396403. 


\section{Obstetrics \& Gynecology Science}

Vol. 65, No. 1, 2022

5. Tegerstedt G, Maehle-Schmidt M, Nyrén O, Hammarström M. Prevalence of symptomatic pelvic organ prolapse in a Swedish population. Int Urogynecol J Pelvic Floor Dysfunct 2005;16:497-503.

6. Kim SH. Diagnosis and treatment of pelvic organ prolapse. Korean J Obstet Gynecol 2006;49:501-12.

7. Yuk JS, Lee JH, Hur JY, Shin JH. The prevalence and treatment pattern of clinically diagnosed pelvic organ prolapse: a Korean National Health Insurance Database-based cross-sectional study 2009-2015. Sci Rep 2018;8:1334.

8. Dietz HP. Prolapse worsens with age, doesn't it? Aust N Z J Obstet Gynaecol 2008;48:587-91.

9. Inal ZO, Inal HA. Comparison of abdominal, vaginal, and laparoscopic hysterectomies in a tertiary care hospital in Turkey. Ir J Med Sci 2018;187:485-91.

10. Roovers JP, van der Bom JG, van der Vaart $\mathrm{CH}$, Schagen van Leeuwen JH, Heintz AP. Abdominal versus vaginal approach for the management of genital prolapse and coexisting stress incontinence. Int Urogynecol J Pelvic Floor Dysfunct 2002;13:224-31.

11. Johnson N, Barlow D, Lethaby A, Tavender E, Curr E, Garry R. Surgical approach to hysterectomy for benign gynaecological disease. Cochrane Database Syst Rev 2005;(1):CD003677.

12. Jeon MJ. Surgical decision making for symptomatic pelvic organ prolapse: evidence-based approach. Obstet Gynecol Sci 2019;62:307-12.

13. Dallas K, Elliott CS, Syan R, Sohlberg E, Enemchukwu E, Rogo-Gupta L. Association between concomitant hysterectomy and repeat surgery for pelvic organ prolapse repair in a cohort of nearly 100,000 women. Obstet Gynecol 2018;132:1328-36.

14. Glazener CM, Breeman S, Elders A, Hemming C, Cooper $K G$, Freeman RM, et al. Mesh, graft, or standard repair for women having primary transvaginal anterior or posterior compartment prolapse surgery: two parallelgroup, multicentre, randomised, controlled trials (PROSPECT). Lancet 2017;389:381-92.

15. Dos Reis Brandão da Silveira S, Haddad JM, de JármyDi Bella ZI, Nastri F, Kawabata MG, da Silva Carramão $S$, et al. Multicenter, randomized trial comparing native vaginal tissue repair and synthetic mesh repair for genital prolapse surgical treatment. Int Urogynecol J 2015;26:335-42.
16. Ko KJ, Lee KS. Current surgical management of pelvic organ prolapse: strategies for the improvement of surgical outcomes. Investig Clin Urol 2019;60:413-24.

17. Mowat A, Maher D, Baessler K, Christmann-Schmid C, Haya N, Maher C. Surgery for women with posterior compartment prolapse. Cochrane Database Syst Rev 2018;3:CD012975.

18. Roovers JP, van der Vaart $\mathrm{CH}$, van der Bom JG, van Leeuwen JH, Scholten PC, Heintz AP. A randomised controlled trial comparing abdominal and vaginal prolapse surgery: effects on urogenital function. BJOG 2004; 111:50-6.

19. Persu C, Chapple CR, Cauni V, Gutue S, Geavlete P. Pelvic organ prolapse quantification system (POP-Q) - a new era in pelvic prolapse staging. J Med Life 2011;4:75-81.

20. Ismail S, Duckett J, Rizk D, Sorinola O, Kammerer-Doak D, Contreras-Ortiz O, et al. Recurrent pelvic organ prolapse: International Urogynecological Association research and development committee opinion. Int Urogynecol J 2016;27:1619-1632.

21. Maher C, Feiner B, Baessler K, Christmann-Schmid C, Haya N, Brown J. Surgery for women with anterior compartment prolapse. Cochrane Database Syst Rev 2016;11:CD004014.

22. Maher C, Feiner B, Baessler K, Christmann-Schmid C, Haya $N$, Brown J. Surgery for women with apical vaginal prolapse. Cochrane Database Syst Rev 2016;10: CD012376.

23. Nager CW, Visco AG, Richter HE, Rardin CR, Rogers RG, Harvie HS, et al. Effect of vaginal mesh hysteropexy vs vaginal hysterectomy with uterosacral ligament suspension on treatment failure in women with uterovaginal prolapse: a randomized clinical trial. JAMA 2019;322:1054-65.

24. O'Leary BD, Dempsey M, Agnew GJ. Blood transfusion after vaginal hysterectomy for pelvic organ prolapse. Ir J Med Sci 2019;188:265-6.

25. Otton GR, Mandapati S, Streatfeild KA, Hewson AD. Transfusion rate associated with hysterectomy for benign disease. Aust N Z J Obstet Gynaecol 2001;41:43942.

26. Nelson NC, Ostby SA, Weaver AL, McGree ME, Gebhart JB, Bakkum-Gamez JN. Estimated blood loss during vaginal hysterectomy and adnexal surgery described with an intraoperative pictographic tool. Female Pelvic Med 


\section{Obstetrics \& Gynecology Science}

Ju Hee Kim, et al. Efficacy of vaginal hysterectomy

Reconstr Surg 2018;24:347-51.

27. Clarke-Pearson DL, Geller EJ. Complications of hysterectomy. Obstet Gynecol 2013;121:654-73.

28. Chong C, Kim HS, Suh DH, Jee BC. Risk factors for urinary retention after vaginal hysterectomy for pelvic organ prolapse. Obstet Gynecol Sci 2016;59:137-43.
29. Mathevet P, Valencia P, Cousin C, Mellier G, Dargent D. Operative injuries during vaginal hysterectomy. Eur J Obstet Gynecol Reprod Biol 2001;97:71-5.

30. Vergeldt TF, Weemhoff M, IntHout J, Kluivers KB. Risk factors for pelvic organ prolapse and its recurrence: a systematic review. Int Urogynecol J 2015;26:1559-73. 